\title{
Characterisation of the rhizoremediation of petroleum-contaminated soil: effect of different influencing factors
}

\author{
J. C. Tang, R. G. Wang, X. W. Niu, M. Wang, H. R. Chu, and Q. X. Zhou \\ College of Environmental Science and Engineering, Nankai University/Key Laboratory of Pollution Processes and \\ Environmental Criteria, Ministry of Education, Tianjin, 300071, China
}

Received: 3 April 2010 - Published in Biogeosciences Discuss.: 16 June 2010

Revised: 22 September 2010 - Accepted: 21 October 2010 - Published: 3 December 2010

\begin{abstract}
Pilot experiments were conducted to analyse the effect of different environmental factors on the rhizoremediation of petroleum-contaminated soil. Different plant species (cotton, ryegrass, tall fescue and alfalfa), the addition of fertilizer, different concentrations of total petroleum hydrocarbons (TPH) in the soil, bioaugmentation with effective microbial agents (EMA) and plant growth-promoting rhizobacteria (PGPR) and remediation time were tested as influencing factors during the bioremediation process of TPH. The results show that the remediation process can be enhanced by different plant species. The order of effectiveness of the plants was the following: tall fescue $>$ ryegrass $>$ alfalfa $>$ cotton. The degradation rate of TPH increased with increased fertilizer addition, and a moderate urea level of $20 \mathrm{~g} \mathrm{~N}$ (Nitrogen) $/ \mathrm{m}^{2}$ was best for both plant growth and TPH remediation. A high TPH content is toxic to plant growth and inhibits the degradation of petroleum hydrocarbons. The results showed that a 5\% TPH content gave the best degradation in soil planted with ryegrass. Bioaugmentation with different bacteria and PGPR yielded the following results for TPH degradation: cotton+EMA+PGPR $>$ cotton+EMA $>$ cotton+PGPR $>$ cotton $>$ control. Rapid degradation of TPH was found at the initial period of remediation caused by the activity of microorganisms. A continuous increase of degradation rate was found during the 30-90 days period followed by a slow increase during the $90-150$ days period. These results suggest that rhizoremediation can be enhanced with the proper control of different influencing factors that affect both plant growth and microbial activity in the rhizosphere environment.
\end{abstract}

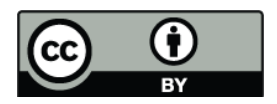

Correspondence to: J. C. Tang (tangjch@ nankai.edu.cn)

\section{Introduction}

With the development of the economy and petroleum exploration, the contamination of soil with petroleum compounds is a concern worldwide (Banks et al., 2003; Rojo, 2009). Bioremediation of contaminated soil is low cost, causes less interference with the soil structure and has a higher public acceptance than other approaches including soil thermal desorption and soil leaching treatment. There are two different approaches for the bioremediation of petroleumcontaminated soil: microbial remediation and phytoremediation. Phytoremediation is a strategy that uses plants to degrade, stabilise, and/or remove soil contaminants. Phytoremediation of hydrocarbons has the potential to be a sustainable waste management technology if it can be proven to be effective in the field (Gurska et al., 2009). Recently, the combination of microbial remediation and phytoremediation has become a general practice in the field treatment of petroleumcontaminated soils. This technique can be defined as rhizoremediation, which is a specific type of phytoremediation that involves both plants and their associated rhizosphere microbes. The process can occur naturally or can be actuated by deliberately introducing specific microbes (Gerhardta et al., 2009).

The contamination of crude oil results in an immediate change in the bacterial community structure, an increasing abundance of hydrocarbon-degrading microorganisms and a rapid rate of oil degradation, which suggests the presence of a pre-adapted, oil-degrading microbial community and sufficient supply of nutrients (Coulon et al., 2006; Hamamura et al., 2006). The degradation rates of microbial remediation and phytoremediation greatly differ, depending on several conditions. Microbial degradation can be accomplished by different species of microorganisms that are both native

Published by Copernicus Publications on behalf of the European Geosciences Union. 
to the soil and added as effective degrading strains. The microbial degradation is generally higher than $40 \%$ within 1 year of disposal and may be as high as $70 \%$ in some cases (Sathishkumar et al., 2008). Influencing factors for microbial remediation include soil moisture content, soil temperature, soil $\mathrm{pH}$, oxygen supply, nutrients, oxidation-reduction potential, soil texture and soil structure (Riser-Roberts, 1998). However, the degradation rate in phytoremediation is generally low; it may be as low as only $9.1 \%-20 \%$ higher than that of the control soil (Brandt et al., 2006; Euliss et al., 2008). Accordingly, bioaugmentation is needed to introduce effective microorganisms to improve the efficiency of rhizoremediation. The synergistic reaction of the plants and microorganisms, rhizoremediation showed a higher degradation rate of petroleum pollutants than microbial remediation and phytoremediation (Gurska et al., 2009; Xin et al., 2008; Escalante-Espinosa et al., 2005). Several plant species, including ryegrass, sorghum, maize, alfalfa, Bermuda grass, rice, legume, sorghum and beggar ticks, are effective in degrading total petroleum hydrocarbons (TPH) (Nedunuri et al., 2000; Kaimi et al., 2007; Merkl et al., 2005; Shirdam et al., 2008). The TPH content is an important factor of rhizoremediation and influences the bioremediation process. A high TPH content is toxic to both microorganisms and plants. Some plants are sensitive to oil pollution, and plant growth may be greatly reduced in a high-TPH soil (Peng et al., 2009). By using ryegrass and plant growth-promoting rhizobacteria (PGPR) in a rhizoremediation process, the degradation rate in soil with a TPH content of $13 \%$ was $61.5 \%$ during 3 years of remediation (Gurska et al., 2009). When the TPH content was $5 \%$, the process removed $90 \%$ of all TPH fractions from the soil, whereas phytoremediation alone was only able to remove about $50 \%$ of the TPH in the same time period (Huang et al., 2005). These results suggest that a high TPH content inhibits plant growth and microbial activity in the rhizosphere environment, which then results in low TPH degradation. Other factors affecting the rhizoremediation process include inoculation, the addition of nutrients, soil organic content, soil depth and salt content (Mishra et al., 2001; Margesin et al., 2003; Lin and Mendelssohn, 1998; Hutchinson et al., 2001; Keller et al., 2008).

Despite our understanding of the mechanisms of remediation and the successful results in the laboratory and greenhouse, efforts to translate bioremediation research to the field have been challenging (Gerhardta et al., 2009), which is partially because plant growth in the field is generally different from that under laboratory conditions. Furthermore, the field remediation can be affected by many different factors. Currently, systematic research on the influencing factors of rhizoremediation is lacking even though various rhizoremediation techniques for petroleum-contaminated soil have been applied in both laboratory and field experiments. For a better understanding of the mechanisms of remediation and the enhancement of the remediation efficiency, a series of rhizoremediation experiments was conducted and compared to
Table 1. Chemical properties of the soil used in the experiment.

\begin{tabular}{cccccccccc}
\hline pH & TPH\% & Total & Total & \multicolumn{6}{c}{ Heavy metal $(\mathrm{mg} / \mathrm{kg})$} \\
& & $\mathrm{N}(\mathrm{g} / \mathrm{kg})$ & $\mathrm{P}(\mathrm{g} / \mathrm{kg})$ & $\mathrm{Zn}$ & $\mathrm{Cd}$ & $\mathrm{Ni}$ & $\mathrm{Cu}$ & $\mathrm{Pb}$ & $\mathrm{Cr}$ \\
\hline 7.9 & 10 & 2.75 & 0.11 & 666 & - & 6.5 & 16.5 & - & 12 \\
\hline
\end{tabular}

- indicates values below the detection limit of $0.1 \mathrm{mg} / \mathrm{kg}$

further understand how different factors affect the rhizoremediation process and how the remediation process can be controlled for better disposal of TPH-contaminated soil.

\section{Materials and methods}

\subsection{Petroleum-contaminated soil}

Petroleum-contaminated soil was brought from the Shengli Oil Field in China. The soil was air dried and ground to 20 meshes before using. The chemical properties of the soil are shown in Table 1 . The $\mathrm{pH}$ was relatively high, and high TPH and $\mathrm{Zn}$ contents were found in the soil. The TPH content was about $10 \%$, and different concentrations of petroleumcontaminated soil were prepared by mixing the contaminated and un-contaminated soil in different ratios.

\subsection{Experiments for different influencing factors of rhizoremediation}

The following five experimental series were designed to study different influencing factors on the effect of rhizoremediation. (1) Comparison of different species regarding the remediation of TPH. The following four plant species were selected based on literature reports showing that these plants have been used for the remediation of petroleum pollutants: cotton (Gossypium hirsutum Linn), ryegrass (Lolium perenne L.), tall fescue (Festuca arundinacea) and alfalfa (Medicago sativa). The soil TPH content was 5\%, and the experiment was carried out in flower pots with $750 \mathrm{~g}$ of soil for 150 days. The plants were managed based on their general requirements. The TPH content was tested after the remediation process. (2) Effect of chemical fertilizer addition on the remediation process. Urea was added to the TPHcontaminated soil at rates of $0 \mathrm{~g} \mathrm{~N}$ (Nitrogen) $/ \mathrm{m}^{2}, 5 \mathrm{~g} \mathrm{~N} / \mathrm{m}^{2}$, $10 \mathrm{~g} \mathrm{~N} / \mathrm{m}^{2}, 20 \mathrm{~g} \mathrm{~N} / \mathrm{m}^{2}$ and $30 \mathrm{~g} \mathrm{~N} / \mathrm{m}^{2}$, using the same soil as described in the previous experiment. Tall fescue was used as the remediation plant, and the TPH content was analysed and plant biomass was weighed after 150 days of remediation. (3) The effect of TPH content on the growth of plants and the remediation effect. TPH contents of $2 \%, 5 \%$ and $10 \%$ were prepared, and tall fescue was planted for a period of 150 days. The degradation rates were calculated based on the change of TPH content before and after the remediation. (4) Effect of bioaugmentation on the remediation process. Pot experiment was carried out using $750 \mathrm{~g}$ of 
petroleum-contaminated soil at a TPH concentration of 5\%. Cotton was used in this experiment to study the combined effect of plants and EMA, which has not previously been reported. The following five treatments were used: (a) control, (b) planting cotton, (c) planting cotton and the addition of $2 \%$ effective microbial agents (EMA), (d) cotton+PGPR, and (e) cotton+EMA+PGPR. The EMA consisted of 2 microbial strains: Acinetobacter radioresistens and Rhodococcus erythropolis. The bacteria were incubated to over $1 \times 10^{10} \mathrm{cfu} / \mathrm{g}$ in liquid media and added to the peat in a ratio of 1:4 (w/w) to produce the microbial agents. PGPR contained mainly Azospirillum Brasilence, which was bought from Shanghai Pengxie Co., Ltd. The cotton seeds were soaked in the PGPR solution before planting. TPH content, dehydrogenase activity and PCR-DGGE analyses were carried out on the samples during bioaugmentation process. (5) Degradation of pollutants at different times throughout the rhizoremediation process. The following three treatments were used: (a) control, (b) addition of 2\% EMA (Acinetobacter radioresistens and Rhodococcus erythropolis), and (c) addition of 2\% EMA with the planting of tall fescue. Samples were taken after days $0,15,30,45,60,90$ and 150 to study the dynamic change of TPH content during the remediation process.

Filter paper was placed at the bottom of the flower pot to cover the drainage hole, and TPH-contaminated soil was added. For cotton planting, 20 seeds were arranged evenly in each pot and covered with $2-3 \mathrm{~cm}$ of soil on the top. For tall fescue, ryegrass and alfalfa, $5 \mathrm{~g}$ of seed were added evenly to the soil in each pot and covered with $0.5-1 \mathrm{~cm}$ of soil on the top. Water was then added to maintain a soil moisture of $60-90 \%$ of the maximum water holding capacity. No fertilizer was added during the remediation process. In experiment 2, different amounts of urea were added to the TPHcontaminated soil that was placed in the flower pot, and the soil was then mixed thoroughly.

\subsection{Analysis of TPH}

The TPH content was analysed by air-drying 5-g subsamples of the soil. The samples then underwent ultrasound extraction with $15 \mathrm{~mL}$ of chloroform for $15 \mathrm{~min}$ followed by centrifugation at $4000 \mathrm{rpm}$. The supernatant was then filtrated and placed in a flask. The extraction procedure was repeated 3 times, and the extracts were concentrated by drying with a rotary evaporator at $40^{\circ} \mathrm{C}$. The samples were then dried to constant weights at $60^{\circ} \mathrm{C}$, and the flask was reweighed to determine the petroleum hydrocarbon contents.

\subsection{Dehydrogenase activity analysis}

The soil was air-dried, and a 5-g sample was placed in a flask. A solution consisting of $5 \mathrm{~mL}$ of $0.1 \%$ TTC $(2,3,5-$ triphenyltetrazolium Chloride) and $2 \mathrm{~mL}$ of $0.2 \mathrm{M}$ Tris- $\mathrm{HCl}$ buffer solution ( $\mathrm{pH}$ 7.6) was added to the flask, which was then mixed and shaken. A blank was prepared with no addi- tion of TTC. The prepared samples were incubated at $37^{\circ} \mathrm{C}$ for $24 \mathrm{~h}$. After incubation, a $1 \mathrm{M} \mathrm{H}_{2} \mathrm{SO}_{4}$ solution was used to stop the reaction, and $5 \mathrm{~mL}$ of toluene was added. The flasks were then incubated for $30 \mathrm{~min}$ with shaking. After centrifugation, the absorbance of the organic solution was detected at $492 \mathrm{~nm}$, and the dehydrogenase activity was expressed as the amount of TPF (Triphenyl formazan) produced by the reduction of TTC.

\subsection{Denaturing gradient gel electrophoresis (DGGE) analysis of partial 16S rRNA genes}

DNA extraction was carried out using a ZR Soil Microbe DNA Kit ${ }^{\mathrm{TM}}$ (Orange, CA). The procedure of the DNA extraction from soil was performed according to the manufacturer's instructions. The 16S rDNA genes were amplified with PCR using the following primers: 357f-GC clamp (forward, 5'CGCCCGCCGCGCGCGGCGGGCGGGGCGGGGGCAC GGGGGGCCTACGGGAGGCAGCAG-3', Escherichia coli position: 341-357; the underlined sequence corresponds to the GC clamp) and $517 \mathrm{r}$ (reverse, 5'ATTACCGCGGCTGCTGG-3', Escherichia coli position: 517-534). The reaction solution for the PCR contained $0.5 \mu \mathrm{l}$ of each primer, $2.5 \mu \mathrm{l}$ of $10 \mathrm{X}$ Ex Taq buffer, $2.5 \mu \mathrm{l}$ of $2.5 \mathrm{mM}$ dNTP mixture, $2.0 \mu \mathrm{l}$ of bovine serum albumin (BSA), $1.5 \mu \mathrm{l}$ of $25 \mathrm{M} \mathrm{Mg}^{2+}, 0.25 \mu \mathrm{l}$ of $5 \mathrm{U} / \mu \mathrm{l}$ Ex Taq DNA polymerase (TaKaRa, Otsu, Japan), $1.0 \mu$ of DNA template and $14.75 \mu \mathrm{l}$ of ultrapure sterile water. The PCR was carried out by a TaKaRa PCR Thermal Cycler Dice Model TP600 (TakaRa, Otsu, Japan) with the following conditions for amplification: initial denaturation at $94^{\circ} \mathrm{C}$ for $3 \mathrm{~min}, 25$ cycles at $1 \mathrm{~min}$ each of denaturation at $94^{\circ} \mathrm{C}, 1 \mathrm{~min}$ of annealing at $55^{\circ} \mathrm{C}$ and $2 \mathrm{~min}$ of extension at $72^{\circ} \mathrm{C}$, followed by a final extension at $72^{\circ} \mathrm{C}$ for $7 \mathrm{~min}$.

DGGE analysis was used to obtain fingerprinting of the PCR products of partial $16 \mathrm{~S}$ rDNA genes. The denaturing gradient of polyacrylamide ranged from $30 \%$ to $60 \%$. The PCR products were used to perform gel electrophoresis in a cell D-code TM system (Bio-Rad laboratories, Hercules, CA, USA) at $60^{\circ} \mathrm{C}$ and $200 \mathrm{~V}$ for $4 \mathrm{~h}$. The gel was then stained with ethidium bromide (EB) for $30 \mathrm{~min}$ and photographed under UV light. The DGGE bands were analysed by Quantity One (Bio-Rad laboratories, Hercules, CA, USA).

\section{Results}

\subsection{Effects of different plant species on the remediation process of TPH}

Different plant species have been used in the phytoremediation process of petroleum-contaminated soil. Grass of tall fescue and ryegrass as well as alfalfa are generally used and are effective in enhancing the bioremediation of TPH. Cotton is an economic crop that has adapted to saline and alkaline 


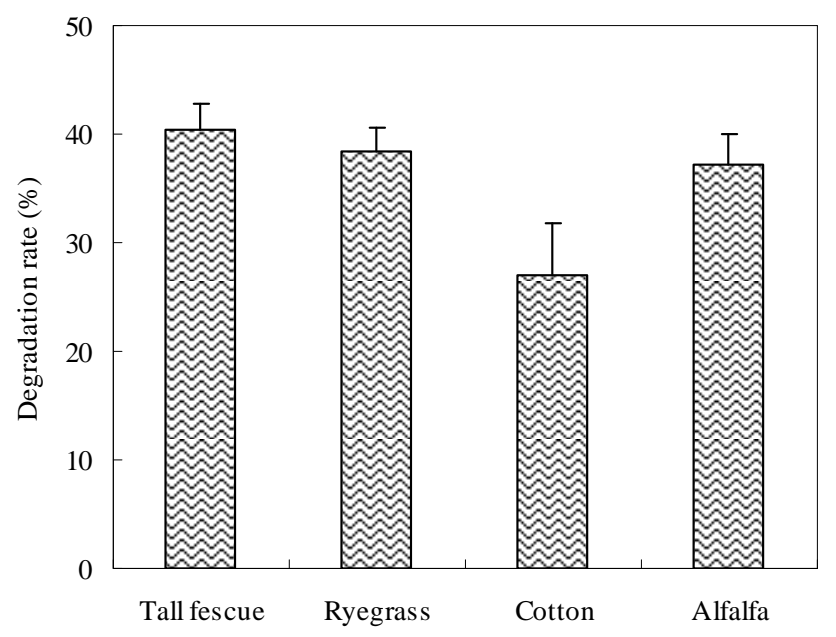

Fig. 1. Comparison of the abilities of different plant species to bioremediate TPH.

soils. The effects of different plant species on the remediation of TPH are shown in Fig. 1. The degradation of TPH ranged from $33.1 \%$ to $48.6 \%$ with the following order of effectiveness of the plants: tall fescue $>$ ryegrass $>$ alfalfa $>$ cotton. The values of degradation in tall fescue and ryegrass were almost the same and were only slightly higher than that of alfalfa. The different degradation rates of TPH in different plants were likely caused by the different physiological functions of roots in the different plants and suggest that the proper selection of plant species is an important strategy in the bioremediation process of TPH.

\subsection{Effect of chemical fertilizer addition to the remediation process}

As both microbial activity and plant growth can be affected by the addition of fertilizer, fertilizer addition is an important factor in determining the efficiency of the bioremediation process. Figure 2a shows the degradation rate of TPH with different addition rates of urea. A positive relationship between the degradation rate of TPH and the addition rate of urea indicates that fertilizer is effective in enhancing the rhizoremediation process of TPH. Figure $2 b$ shows the change of biomass weight with the addition of different amounts of urea. Both wet and dry weights of tall fescue increased with the increase in urea when the application rate was under $20 \mathrm{~g} \mathrm{~N} / \mathrm{m}^{2}$. However, when the application rate was increased to $30 \mathrm{~g} \mathrm{~N} / \mathrm{m}^{2}$, a low biomass weight was found. The highest biomass value of $6.28 \mathrm{~g}$ was achieved when the urea addition was $20 \mathrm{~g} \mathrm{~N} / \mathrm{m}^{2}$, which was approximately 6 times higher than when the urea addition was $30 \mathrm{~g} \mathrm{~N} / \mathrm{m}^{2}$.
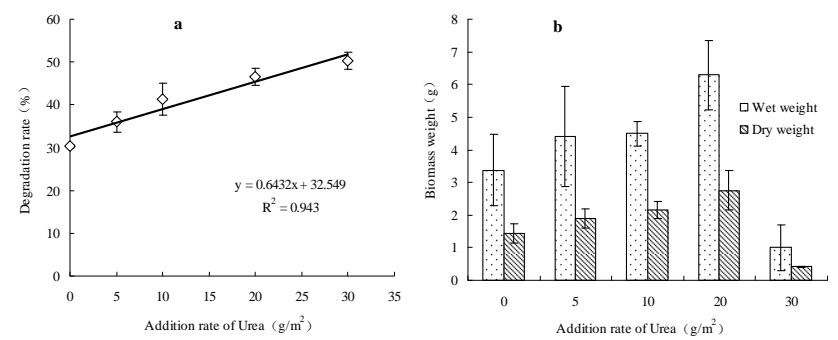

Fig. 2. The effect of urea addition on the bioremediation of TPH.

\subsection{Effect of TPH concentration on plant growth and remediation effectiveness}

Petroleum is toxic to plants, therefore, high concentrations of TPH inhibit plant growth. Figure 3 shows the degradation of TPH at various concentrations. During the phytoremediation process by tall fescue for 150 days, the degradation rates in soil with TPH concentrations of $2 \%, 5 \%$ and $10 \%$ was $60.3 \%, 48.4 \%$ and $14.9 \%$, respectively. The degradation rates indicate that low concentrations of TPH are favourable for TPH degradation. However, the degradation amount of THP is the highest when a moderate concentration of THP is present (Fig. 3). Proper evaluation of the TPH concentration should, thus, be considered during the phytoremediation process to achieve the best remediation results.

\subsection{Effect of bioaugmentation on the rhizoremediation process}

The rhizoremediation process is a combined effect of microbial degradation and plant growth. Figure 4 compares the effect of plant growth, addition of EMA and addition of PGPR on the bioremediation process. The TPH degradation order of effectiveness is: cotton+EMA+PGPR > cotton+EMA > cotton+PGPR $>$ cotton $>$ control. The highest degradation rate was $29.8 \%$ and was found in the treatment of cotton with the addition of both EMA and PGPR. This treatment showed a 10\% higher degradation rate than the control, indicating that bioaugmentation with EMA and PGPR is effective in promoting the rhizoremediation process of TPH. When comparing cotton planting with the control, a 5\% higher degradation rate in cotton planting treatment suggested the effectiveness of phytoremediation. However, cotton+EMA and cotton+PGPR planting showed higher degradation rates than those achieved through cotton planting only. Bioaugmentation with petroleum-degrading bacteria is supposed to be able to enhance the rhizoremediation process. Dehydrogenase activity was higher in the four treatments than in the control. The highest value of dehydrogenase activity was achieved with the addition of EMA. However, PGPR did not improve the dehydrogenase activity during the remediation process.

Based on the DGGE analysis results shown in Fig. 5a, more complex microbial communities were found in lanes 


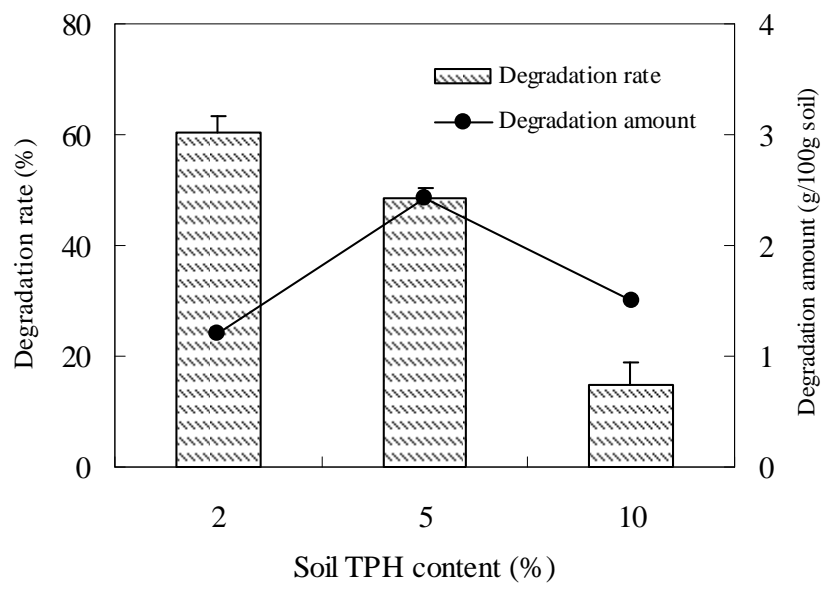

Fig. 3. The effect of soil TPH concentration on the degradation rate.

2-6 compared to that in lane 1 . These results indicate that the rhizoremediation of TPH with cotton and different microorganisms allows the proliferation of the complex microbial community. Some new bands developed during the remediation process. Common bands $\mathrm{C} 1-\mathrm{C} 13$ can be found in all samples of lanes 1-6. Special bands S1-S8 are only observed in certain lanes. S1 was found in lanes 2-6 but not in lane1, S2 was only found in lane 1, S3 was only found in lanes 4 and 5, and S5 was only found in lane 3. The cluster analysis shown in Fig. $5 b$ indicates that the microbial community of the control group was different from that of the cotton planting group. However, the two treatments with the addition of PGPR were grouped into one category by the cluster analysis.

\subsection{Degradation of TPH pollutants at different time throughout the rhizoremediation process}

The rhizoremediation process with tall fescue can be divided into three periods. A rapid increase in the degradation rate was found at the initial period of remediation of days $0-30$, a continuous increase in the degradation rate was found in the following period of days 30-90, and a slight increase in the degradation rate was found from days 90 to 150 . At days 15, the relative degradation rates were: EMA $>$ EMA+plant $>$ control. The degradation rate gradually increased in the EMA+plant treatment and became higher than that of EMA in TPH degradation after day 30. An enhanced remediation effect by planting tall fescue coupled with the addition of EMA (7\% higher than the control and EMA sample) was found after remediation days 90 (Fig. 6).

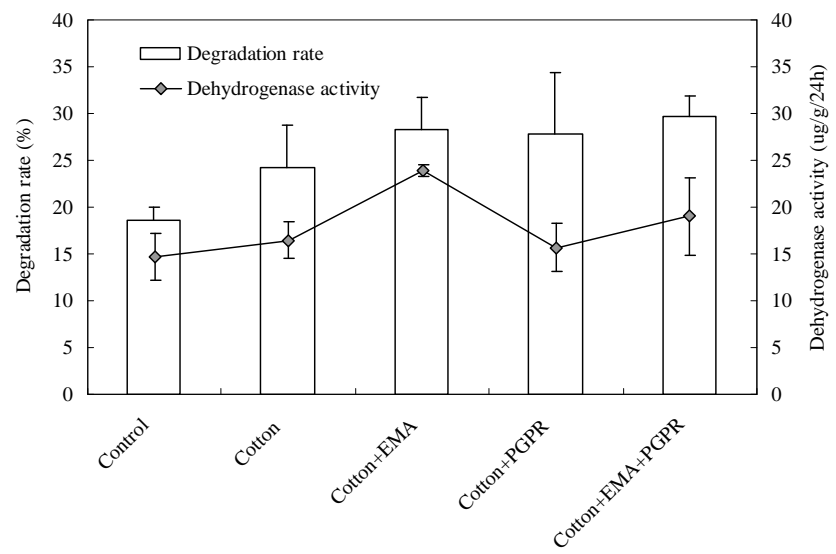

Fig. 4. The effect of EMA and PGPR bacteria on the remediation process.

\section{Discussion}

Regulating the factors influencing the rhizoremediation process is important for achieving an improved degradation of TPH. In this study, plant species, fertilizer addition, TPH concentration, inoculation of microorganisms and remediation time were considered to be the main factors influencing rhizoremediation and were studied in detail. In our research, tall fescue, ryegrass, cotton and alfalfa were compared in rhizoremediation process. These plants were chosen because they grow in a wide range of soil conditions and can withstand high saline-alkali stress, which is common in oil fields in many parts of China. Hydrocarbon contamination is known to significantly reduce the growth of the plants, and the corresponding TPH degradation efficiency of the different plant species is reported to differ widely (Shirdam et al., 2008; Euliss et al., 2008).

The TPH degradation rate among various plant species depends on the microbial population in the rhizosphere of these plants. Many different plant species have been reported to be effective in the remediation of TPH-contaminated soil, including grass, alfalfa, poplar, and ryegrass (Phillips et al., 2009; Euliss et al., 2008; Kechavarzi et al., 2007). It was reported that perennial ryegrass and alfalfa increased the number of rhizosphere bacteria in hydrocarbon-contaminated soil (Kirk et al., 2005). Tall fescue also showed a high TPH degradation rate in petroleum-contaminated soil (Ezzatian et al., 2009). Cotton can grow under conditions of approximately $0.5 \%$ salinity (Ashraf and Ahmad, 2000; Sacchi et al., 2000) and can be grown in the saline-alkaline oil fields in China. However, the degradation rate of TPH by cotton is lower than that of the other three plant species in this study. It was reported by Hou et al. (2001) that rooting intensity ( $\mathrm{mg}$ root $\mathrm{kg}^{-1}$ soil) is the key factor leading to high TPH loss rates, and root development is crucial in evaluating the phytoremediation potential. The well-developed root system of grass is advantageous in enhancing petroleum degradation. 


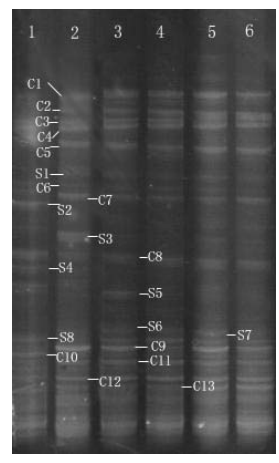

a

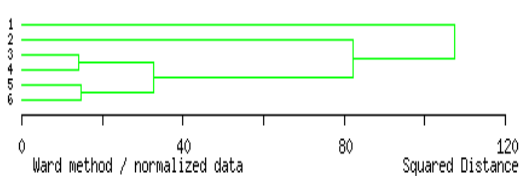

Fig. 5. DGGE analysis results from the TPH bioremediation process (a) and cluster analysis (b). Soil before remediation (1), control (2), cotton (3), cotton+EMA (4), cotton+PGPR (5), and cotton+PGPR+EMA (6).

In contrast, alfalfa has an advantage because of its ability to recruit nitrogen fixing microbes in the soil (Kelner et al., 1997). In addition, cotton is important in phytoremediation because it produces products with high economic value, which might help to sustain the long-term application of field phytoremediation (Banuelos, 2006). It is important to rank the different plant species in TPH degradation. However, the degradation rate is not the only factor used in selecting phytoremediation plants. Plant species should be selected based on the soil condition and remediation purpose.

Microbial degradation rates in TPH-contaminated soil were more affected by soil properties and the chemical characteristics of the contaminant than the presence of roots (Song et al., 2004). This result indicates that research should be focused more on the effects of different soil properties on TPH remediation rather than on the selection of different plant species. The addition of NPK fertilizer and compost was shown to greatly enhance hydrocarbon degradation (Palmroth et al., 2006). Furthermore, a positive correlation between TPH degradation rate and fertilizer addition supports this conclusion and suggests that a moderate amount of fertilizer is required for both better plant growth and higher TPH degradation. The inhibition of plant growth at a urea content of $30 \mathrm{~g} \mathrm{~N} / \mathrm{m}^{2}$ is likely caused by salt toxicity. However, the microbial degradation of TPH was not affected at this urea concentration, as bacteria are tolerant to higher salt contents. Although phosphorus $(\mathrm{P})$ is another factor that might affect plant and microbial growth, our results suggest that $\mathrm{N}$ is the most crucial factor in the rhizoremediation process.

The effect of TPH concentration on the degradation of TPH is likely caused by the toxicity of hydrocarbons on the plants and rhizosphere microorganisms. TPH concentration was the major determinant of total bacterial abundance and affected the abundance of hydrocarbon degraders (Nie et al.,

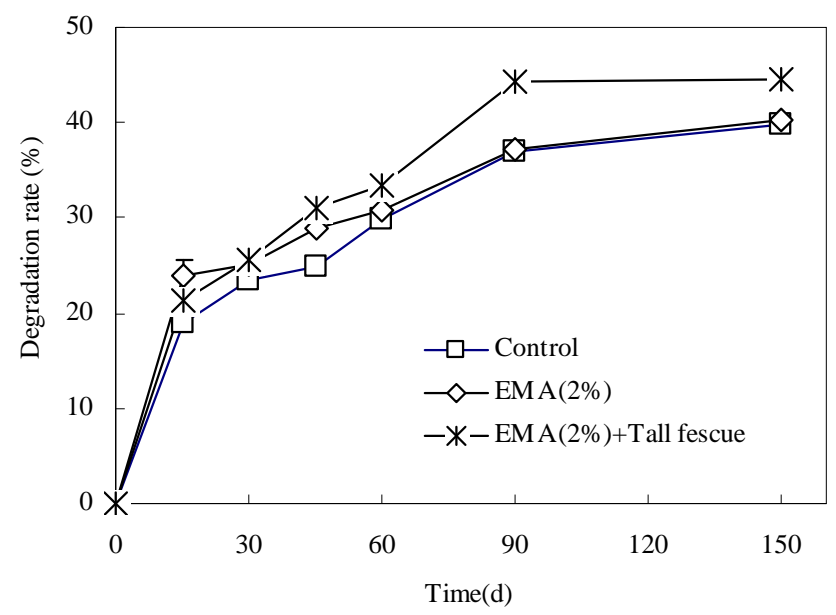

Fig. 6. Degradation of TPH pollutants at different time points during the rhizoremediation process with tall fescue.

2009). The bioremediation of hydrocarbons could be carried out successfully at TPH concentrations of 10-13\% (Del Panno et al., 2005; Gurska et al., 2009), although there is no report of the maximum permissible TPH content for bioremediation. In addition, the optimum TPH content for rhizoremediation is still a question of concern. Earthworms were 1.4 to 14 times more sensitive to TPH than microorganisms and 1.3 to $>77$ times more sensitive to TPH than plants (Dorn et al., 1998), meaning that plants can withstand higher concentrations of TPH than other organisms. A preferential degradation of saturated hydrocarbons was found by Peng et al. (2009), during a phytoremediation trial of TPH using Mirabilis Jalapa L. Light oil fractions were generally more toxic than heavy oil fractions (Dorn et al., 1998), and the preferential degradation of light oil generally causes a decrease in soil toxicity during the TPH degradation process. On the other hand, the degradation of older soil contaminated by TPH is generally more difficult than freshly contaminated soil. Research shows greater rates of hydrocarbon loss in soils containing fresh petroleum products compared with the aged products (Parker and Burgos, 2001). Our results indicate that a moderate TPH concentration (about $5 \%$ ) is favourable for hydrocarbon degradation, which means that biological remediation is most effective in a moderate TPH concentration of contaminated soil immediately after a spill. However, rhizomediation can be carried out successfully even under high TPH concentrations, indicating that further research associated with reducing the toxicity of TPH and enhancing the rhizoremediation process for an improved remediation is necessary.

As TPH reduction is positively correlated with culturable hydrocarbon degraders (Phillips et al., 2006), it is possible that the addition of effective microorganisms enhances the rhizoremediation process of TPH (Gurska et al., 2009; Mishra et al., 2001). Different plant species may introduce 
different microbial communities and increase the total culturable microbial amount during their growth processes. Cotton roots can be colonised by a variety of microorganisms including Fusarium culmorum, F. solani, F. oxysporum, Macrophomina phaseoli and Bacillus sp. (Ghaffar and Parveen, 1969). Some bacteria, such as the Rhodococcus sp. strain, can grow at the oil-water interface and produce a mycolic acid-containing capsule to enhance TPH degradation (Van Hamme and Ward, 2001). A high degradation rate of $85.67 \%$ within 120 days was reached by combining cotton with native microorganisms. The degradation rates were higher when cotton was combined with native microorganisms than when other plant species, such as sunflowers, bermuda grass and sudan grass, were combined with native microorganisms (Liu et al., 2009). The results of the DGGE analysis conducted here show that cotton growth increases microbial diversity and alters the microbial community structure. The inoculated microorganisms will remain active during plant growth conditions and colonise in the root systems of plants. In some cases, the population of introduced strains may remain stable even after one year (Mishra et al., 2001). However, researchers reported that the introduction of exotic microorganisms did not improve the remediation and that the inoculation of oil-contaminated sites with nonindigenous species is likely to fail ( $\mathrm{Li}$ et al., 2002; Thomassin-Lacroix et al., 2002; Cavalca et al., 2002). It is suggested that the effect and efficiency of inoculated microorganism depend on the environmental conditions such as the existence of indigenous microorganisms, nutrient level and amount of inoculation. Microbial degradation combined with phytoremediation will further improve the degradation efficiency. As microbial degradation occurred at the early stage of remediation, an early period of microbial remediation followed by phytoremediation is likely to be effective in the field remediation practice.

It generally takes several months for the bioremediation of TPH to reach a reasonable end point. Our results suggest that the degradation rate of TPH is different at different time during the bioremediation process. It is possible that native microorganisms may also develop at the initial period of bioremediation as indicated by the high degradation of TPH in the control in experiment 5 . While several factors influence rhizoremediation, TPH content is the most important factor. Other factors that can affect the degradation rate include the amount of microbial agents and the addition of fertilizer. As microbial degradation is most effective at the initial period of remediation, a second addition of the microbial agents may be a good strategy during the course of remediation. The regulation of soil conditions such as $\mathrm{pH}$, moisture content and nutrient content is the most important measure for the growth of native microorganisms and plants during the initial phase of rhizoremediation. It is also recommended to use plants with fast growth rates and plants that can become strong enough, such that after only one month they can take over the role of the inoculated microorganisms in maintain- ing the TPH degradation activity for the long term. Thus, the selection of fast growing plants that have long growth periods is an important factor to consider in the combination of microbial remediation and phytoremediation. After 150 days, the degradation rate is stable even when microbial remediation is combined with the planting of tall fescue. Further research should be performed to enhance the bioremediation by multi-process phytoremediation systems such as the addition of fertilizer, management of plant growth and increasing aeration of the rhizosphere environment.

\section{Conclusions}

Grass plants like tall fescue and ryegrass are better for the bioremediation of TPH than alfalfa and cotton, as these plants showed a higher TPH degradation rate. The addition of urea enhanced the degradation of TPH, and a positive correlation between the amount of urea added and the degradation rate of TPH was found. A high TPH content inhibited the bioremediation process likely because of the toxicity of TPH to the plant and bacteria. The optimum TPH concentration for rhizoremediation was determined to be approximately $5 \%$. Bioaugmentation during the phytoremediation process with different bacteria including PGPR was shown to enhance the rhizoremediation process with a degradation rate of $29.8 \%$ after 150 days. Bioaugmentation was effective during the first 30 days, and plant growth enhanced the TPH degradation after several months of remediation. The results suggest that rhizoremediation can be enhanced by controlling the factors that affect both plant growth and microbial activity in the rhizosphere environment.

Because a long time period is needed to conduct bioremediation processes, it is difficult to control all the influencing factors. The TPH content is crucial for rhizoremediation because of its toxicity to plants. Plant selection is also important, as crop management will greatly differ for different plant species. Finally, fertilizer and EMA addition should be applied in the remediation field for better degradation of TPH.

Acknowledgements. This research was supported by (1) The National High Technology Research and Development Program of China (863 Program: 2007AA061201), (2) The Knowledge Innovation Project of The Chinese Academy of Sciences (kzcx1-yw-06-03), and (3) Tianjin Natural Science Foundation (09JCYBJC08800). We also would like to give special thanks to Professor Jianing Wang and Biology Research Institute of Shandong Academy of Science for providing microbial agents in our research.

Edited by: N. Ohte 


\section{References}

Ashraf, M. and Ahmad, S.: Influence of sodium chloride on ion accumulation, yield components and fibre characteristics in salttolerant and salt-sensitive lines of cotton (Gossypium hirsutum L.), Field Crop. Res., 66(2), 115-127, 2000.

Banks, M. K., Mallede, H. and Rathbone, K.: Rhizosphere microbial characterization in petroleum-contaminated soil, Soil Sediment Contam., 12, 371-385, 2003.

Banuelos, G. S.: Phyto-products may be essential for sustainability and implementation of phytoremediation, Environ. Pollut., 144(1), 19-23, 2006.

Brandt, R., Merkl, N., Schultze-Kraft, R., Infante, C., and Broll, G.: Potential of vetiver (Vetiveria zizanioides (L.) Nash) for phytoremediation of petroleum hydrocarbon-contaminated soils in Venezuela, Int. J. Phytoremediat., 8, 273-284, 2006.

Cavalca, L., Colombo, M., Larcher, S., Gigliotti, C., Collina, E., and Andreoni, V.: Survival and naphthalene-degrading activity of Rhodococcus sp. strain 1BN in soil microcosms, J. Appl. Microbiol., 92, 1058-1065, 2002.

Coulon, F., McKew, B. A., Osborn, A. M., McGenity, T. J., and Timmis, K. N.: Effects of temperature and biostimulation on oildegrading microbial communities in temperate estuarine waters, Environ. Microbiol., 9, 177-186, 2006.

Del Panno, M. T., Morelli, I. S., Engelen, B., and Berthe-Corti, L.: Effect of petrochemical sludge concentrations on microbial communities during soil bioremediation, FEMS Microbiol. Ecol., 53(2,1), 305-316, 2005.

Dorn, P. B., Salanitro, J. P., Wisniewski, H. L., and Vipond, T. E.: Assessment of the acute toxicity of crude oils in soils using earthworms, microtox ${ }^{\circledR}$, and plants, Chemosphere, 37, 845-860, 1998.

Escalante-Espinosa, E., Gallegos-Martinez, M. E., Favela-Torres, E., and Gutierrez-Rojas, M.: Improvement of the hydrocarbon phytoremediation rate by Cyperus laxus Lam. inoculated with a microbial consortium in a model system, Chemosphere, 59, 405413, 2005.

Euliss, K., Ho, C. H., Schwab, A. P., Rock, S., and Banks, A. K.: Greenhouse and field assessment of phytoremediation for petroleum contaminants in a riparian zone, Bioresource Technol., 99, 1961-1971, 2008.

Ezzatian, R., Voussoughi, M., Yaghmaei, S., Abedi-Koupai, J., Borghei, M., and Ghafoori, S.: Effects of Puccinellia Distans and Tall Fescue on Modification of $\mathrm{C} / \mathrm{N}$ Ratios and Microbial Activities in Crude Oil-Contaminated Soils, Petrol Sci. Technol. 27, 452-463, 2009.

Gerhardta, K. E., Huang, X. D., Glicka, B. R., and Greenberg, B. M.: Phytoremediation and rhizoremediation of organic soil contaminants: Potential and challenges, Plant Sci. 176, 20-30, 2009.

Gurska, J., Wang, W. X., Gerhardt, K. E., Khalid, A. M., Isherwood, D. M., Huang, X. D., Glick, B. R., and Greenberg, B. M.: Three year field test of a plant growth promoting rhizobacteria enhanced phytoremediation system at a land farm for treatment of hydrocarbon waste, Environ. Sci. Technol., 43(12), 44724479, 2009.

Ghaffar, A. and Parveen, G.: Colonization of cotton roots by soil micro-organisms, Mycopathologia, 38, 373-376, 1969.

Hamamura, N., Olson, S. H., Ward, D. M., and Inskeep, W. P.: Microbial Population Dynamics Associated with Crude-Oil Biodegradation in Diverse Soils, Appl. Environ. Microbiol., 72,
6316-6324, 2006.

Hou, F. S., Milke, M. W., Leung, D. W., and MacPherson, D. J.: Variations in phytoremediation performance with dieselcontaminated soil, Environ. Technol., 22(2), 215-22, 2001.

Huang, X. D., El-Alawi, Y., Gurska, J., Glick, B. R., and Greenberg, B. M.: A multi-process phytoremediation system for decontamination of persistent total petroleum hydrocarbons (TPHs) from soils, Microchem. J., 81, 139-147, 2005.

Hutchinson, S. L., Banks, M. K., and Schwab, A. P.: Phytoremediation of aged petroleum sludge: Effect of inorganic fertilizer, J. Environl. Qual., 30, 395-403, 2001.

Kaimi, E., Mukaidani, T., and Tamaki, M.: Screening of twelve plant species for phytoremediation of petroleum hydrocarboncontaminated soil, Plant Product Sci., 10, 211-218, 2007.

Kechavarzi, C., Pettersson, K., Leeds-Harrison, P., Ritchie, L., and Ledin, S.: Root establishment of perennial ryegrass (L-perenne) in diesel contaminated subsurface soil layers, Environ. Pollut., 145, 68-74, 2007.

Keller, J., Banks, M. K., and Schwab, A. P.: Effect of soil depth on phytoremediation efficiency for petroleum contaminants, J. Environ. Sci. Heal. A, 43, 1-9, 2008.

Kelner, D. J., Vessey, J. K., and Entz, M. H.: The nitrogen dynamics of 1-, 2- and 3-year stands of alfalfa in a cropping system, Agr. Ecosyst. Environ., 64(1), 1-10, 1997.

Kirk, J. L., Klironomos, J. N., Lee, H., and Trevors, J. T.: The effects of perennial ryegrass and alfalfa on microbial abundance and diversity in petroleum contaminated soil, Environ. Pollut., 133, 455-465, 2005.

Li, P., Sun, T., Stagnitti, F., Zhang, C., Zhang, H., Xiong, X., Allinson, G., Ma, X., and Allinson, M.: Field-Scale Bioremediation of Soil Contaminated with Crude Oil, Environ. Eng. Sci., 19, 277-289, 2002.

Lin, Q. X. and Mendelssohn, I. A.: The combined effects of phytoremediation and biostimulation in enhancing habitat restoration and oil degradation of petroleum contaminated wetlands, Ecol. Eng., 10, 263-274, 1998.

Liu, J. C., Cui, Y. S., Zhang, Y. P., and Zou, S. Z.: Effect of Plants and Microorganisms on Remediation of Petroleum Contaminated Soil, J. Ecol. Rural Environ., 25, 80-83, 2009.

Margesin, R., Labbé, D., Schinner, F., Greer, C. W., and Whyte, L. G.: Characterization of Hydrocarbon-Degrading Microbial Populations in Contaminated and Pristine Alpine Soils, Appl. Environ. Microbiol., 69, 3085-3092, 2003.

Merkl, N., Schultze-Kraft, R., and Infante, C.: Assessment of tropical grasses and legumes for phytoremediation of petroleumcontaminated soils, Water Air Soil Pollut., 165, 195-209, 2005.

Mishra, S., Jyot, J., Kuhad, R. C., and Lal, B.: Evaluation of inoculum addition to stimulate in situ bioremediation of oily-sludgecontaminated soil, Appl. Environ. Microbiol., 67, 1675-1681, 2001.

Nedunuri, K. V., Govindaraju, R. S., Banks, M. K., Schwab, A. P., and Chens, Z.: Evaluation of phytoremediation for field-scale degradation of total petroleum hydrocarbons, J. Environ. Eng.ASCE, 126, 483-490, 2000.

Nie, M., Zhang, X. D., Wang, J. Q., Jiang, L. F., Yang, J., Quan, Z. X., Cui, X. H., Fang, C. M., and Li, B.: Rhizosphere effects on soil bacterial abundance and diversity in the Yellow River Deltaic ecosystem as influenced by petroleum contamination and soil salinization, Soil Biol. Biochem. 41(12), 2535-2542, 2009. 
Palmroth, M., Koskinen, P. E. P., Pichtel, J., Vaajasaari, K., Joutti, A., Tuhkanen, T. A., and Jaakko Puhakka, A.: Field-Scale Assessment of Phytotreatment of Soil Contaminated with Weathered Hydrocarbons and Heavy Metals, J. Soils Sediments, 6(3), 128-136, 2006.

Parker, E. F. and Burgos, W. D.: Degradation Patterns of Fresh and Aged Petroleum-Contaminated Soils, Environ. Eng. Sci., 16, $21-$ 29, 1999.

Peng, S., Zhou, Q., Cai, Z., and Zhang, Z.: Phytoremediation of petroleum contaminated soils by Mirabilis Jalapa L. in a greenhouse plot experiment, J. Hazard. Mater., 168, 1490-1496, 2009.

Phillips, L. A., Greer, C. W., Farrell, R. E., and Germida, J. J.: Field-scale assessment of weathered hydrocarbon degradation by mixed and single plant treatments, Appl. Soil Ecol., 42, 9-17, 2009.

Phillips, L. A., Greer, C. W., and Germida, J. J.: Culture-based and culture-independent assessment of the impact of mixed and single plant treatments on rhizosphere microbial communities in hydrocarbon contaminated flare-pit soil, Soil Biol. Biochem., 38, 2823-2833, 2006.

Riser-Roberts, E.: Remediation of Petroleum Contaminated Soils: Biological, Physical, and Chemical Processes, St. Lucie Press, Boca Raton, FL, 1998.

Rojo, F.: Degradation of alkanes by bacteria, Environ. Microbiol. 11, 2477-2490, 2009.

Sacchi, G. A., Abruzzese, A., Lucchini, G., Fiorani, F., and Cocucci, S.: Efflux and active re-absorption of glucose in roots of cotton plants grown under saline conditions, Plant Soil, 220, 1-11, 2000.
Sathishkumar, M., Binupriya, A. R., Baik, S. H., and Yun, S. E.: Biodegradation of crude oil by individual bacterial strains and a mixed bacterial consortium isolated from hydrocarbon contaminated areas, Clean-Soil Air Water, 36, 92-96, 2008.

Shirdam, R., Zand, A. D., Bidhendi, G. N., and Mehrdadi, N.: Phytoremediation of hydrocarbon-contaminated soils with emphasis on the effect of petroleum hydrocarbons on the growth of plant species, Phytoprotection, 89, 21-29, 2008.

Song, Y. F., Song, X. Y., Zhang, W., Zhou, Q. X., and Sun, T. H.: Issues concerned with the bioremediation of contaminated soils, Huan Jing Ke Xue, 25, 129-133, 2004.

Thomassin-Lacroix, E., Eriksson, M., Reimer, K., and Mohn, W.: Biostimulation and bioaugmentation for on-site treatment of weathered diesel fuel in Arctic soil, Appl. Microbiol. Biotechnol., 59, 551-556, 2002.

Van Hamme, J. D. and Ward, O. P.: Physical and Metabolic Interactions of Pseudomonas sp. Strain JA5-B45 and Rhodococcus sp. Strain F9-D79 during Growth on Crude Oil and Effect of a Chemical Surfactant on Them, Appl. Environ. Microbiol., 67, 4874-4879, 2001.

Xin, L., Li, X. J., Li, P. J., Li, F., Lei, Z., and Zhou, Q. X.: Evaluation of plant-microorganism synergy for the remediation of diesel fuel contaminated soil, Bull. Environ. Contam. Toxicol., 81, 1924, 2008. 